\title{
Influence of Intensive Light Exposure on the Complex Impedance of Polymer Light-Emitting Diodes
}

\author{
Fábio Rogério Cury ${ }^{\mathrm{a} *}$, Thiago Cazati ${ }^{\mathrm{b}}$, Rodrigo Fernando Bianchi ${ }^{\mathrm{a}}$ \\ a'Departamento de Física, Campus Morro do Cruzeiro, Universidade Federal de Ouro Preto \\ 35400-000 Ouro Preto - MG, Brazil \\ ${ }^{\mathrm{b}}$ Instituto de Fisica de Sao Carlos, Univesidade de Sao Paulo \\ Avenida Trabalhador Sao Carlense, 400, 13560-970 São Carlos - SP, Brazil
}

Received: December 5, 2007; Revised: June 3, 2008

\begin{abstract}
In this work we investigated the effect of visible radiation on the electrical properties of poly[(2-methoxy5-hexyloxy)-p-phenylenevinylene]-MH-PPV films and light emitting diodes. Complex impedance measurements of (Au or ITO)/MH-PPV/(Au or Al) samples were carried out at room temperature and exposed to white light. Over the frequency range from $100 \mathrm{mHz}$ to $2 \mathrm{MHz}$, the electrical results of Au/MH-PPV/Au was dominated by the ColeCole approach, where the electrode influence is negligible. However, some additional influence of the interface was observed to occur when $\mathrm{Al}$ was used as electrode. These effects were observed under both dark and visible-light illumination conditions. A simple model based on resistor-capacitor parallel circuits was developed to represent the complex impedance of the samples, thereby separating bulk and interface contributions. We observed that the polymer electrical resistivity decreased while the dielectric constant of the polymer and the thickness of the $\mathrm{Al} / \mathrm{MH}$ PPV layer were almost constant with increasing light intensity. The decrease of the polymer layer resistance comes from a better charge injection due to a light induced dissociation of positive charge carriers at the electrode.
\end{abstract}

Keywords: polymer, device, photoconductivity, interface

\section{Introduction}

Since the first report of polymer light-emitting diodes (PLED) in $1990^{1}$, there has been a considerable effort to improve the efficiency and understanding the electrical properties of such devices. However, many aspects related to the carrier transport mechanisms remain unclear or is somewhat controversial ${ }^{2,3}$. For example, although the carrier transport mechanism through the electroluminescent polymers is usually described as a stochastic process between hopping sites, the carrier injection from the electrode into the polymer is frequently attributed to tunneling of electrons and holes in polymer rigid bands. From this point of view, the ac conductivity appears as a powerful technique able to investigated the electrical properties of PLEDs, since it can be used to study not only the carrier transport mechanism ${ }^{4}$ through the polymer bulk, but also to investigate the influence of the polymer-electrode interfacial layer ${ }^{5}$, as well as the influence of humidity, light exposure, temperature etc. in the optical and/or electrical characteristics of such devices ${ }^{6}$. In this context, the goal of this paper is to progress in the elucidation of the effect of light-induced conductivity variation of polymer light-emitting diodes when exposed to visible radiation.

\section{Experimental Procedure}

Poly[(2-methoxy-5-hexyloxy)-p phenylenevinylene]-MH-PPV was chemically synthesized using a method described elsewhere ${ }^{7}$. MH-PPV solution (6\% (wt)) in chloroform was spincoating on glass recovered with a thin indium-tin oxide (ITO) films and on a gold layer, previously deposited on glass/chromium substrates. Gold and aluminum metallic cathodes were thermally evaporated on the polymer layer, where the electrode area (A) is around $3 \times 10^{-5} \mathrm{~m}^{2}$ and polymer thickness (L) around $400 \mathrm{~nm}$ obtained by atomic force microscopy (AFM). Figure 1 shows the polymer film and light-emitting diodes structures configurations. Current density vs. voltage (J vs. V) curves were carried out in a Keithley 237 Unit, while complex impedance measurements, $z^{*}(f)=z^{\prime}(f)$ - iz" (f), on the other hand, were carried out in a 1260 Solartron Frequency Response Analyzer in the $100 \mathrm{mHz}$ to $2 \mathrm{MHz}$ frequency range, oscillation amplitude equal to $50 \mathrm{mV}$. The incident light was provided by a $250 \mathrm{~W}$ tungsten lamp served as a source of white dichroic light, which has focused onto the entrance window of the cryostat. Different intensities of light $(0.60$ or $250 \mathrm{~mW} . \mathrm{cm}^{2}$ ) illuminated the sample in order to investigate the effects of illumination on their electrical behavior. To prevent photooxidation, the samples were placed in a vacuum cryostat at pressure $\sim 10^{-5}$ Torr. All measurements were performed at room temperature $(300 \mathrm{~K})$ in a dark room and only conducted after the samples were illuminated up to 5 minutes.

\section{Experimental Results}

Figure 2 shows the current density vs. voltage (J vs. V) curves of ITO/MH-PPV/Al structure presented in Figure 1. The measurements were carried out in under different illumination conditions (dark, $60 \mathrm{~mW} . \mathrm{cm}^{-2}$ and $250 \mathrm{~mW} . \mathrm{cm}^{-2}$ ). From these results, the typical Schottky diodes behavior is observed, in which the threshold voltage (V0) is around $1.0 \mathrm{~V}$ for all intensities. After threshold, the current density of ITO/MH-PPV/Al device is directly proportional to light intensity suggesting that the dc electrical resistivity of the polymer film (obtained from Ohm's Law for $\mathrm{V}>\mathrm{V}_{0}$ ) decreases with increasing the intensity. It means that this polymer shows photo-conductivity behavior. Furthermore, non-linear current-voltage dependence has been observed in poly(p-phenylenevinylene) derivatives light-emitting diodes when ITO-Al were used as electrodes ${ }^{4}$, which contrast with the linear dependence (or ohmic behavior), observed when ITO$\mathrm{Au}$ or $\mathrm{Au}-\mathrm{Au}$ were used as electrodes ${ }^{8,9}$. This linear dependence is explained in terms of ohmic contact obtained from the ionization 


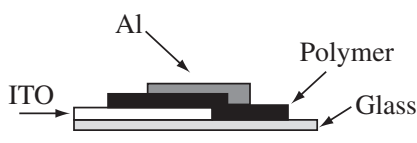

(a)

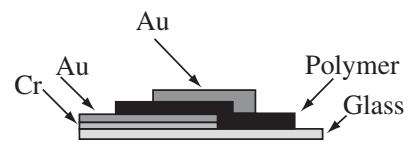

(b)
Figure 1. Schematic representations of the polymer structures used in this work. a) ITO/MH-PPV/Al and b) Au/MH-PPV/Au.

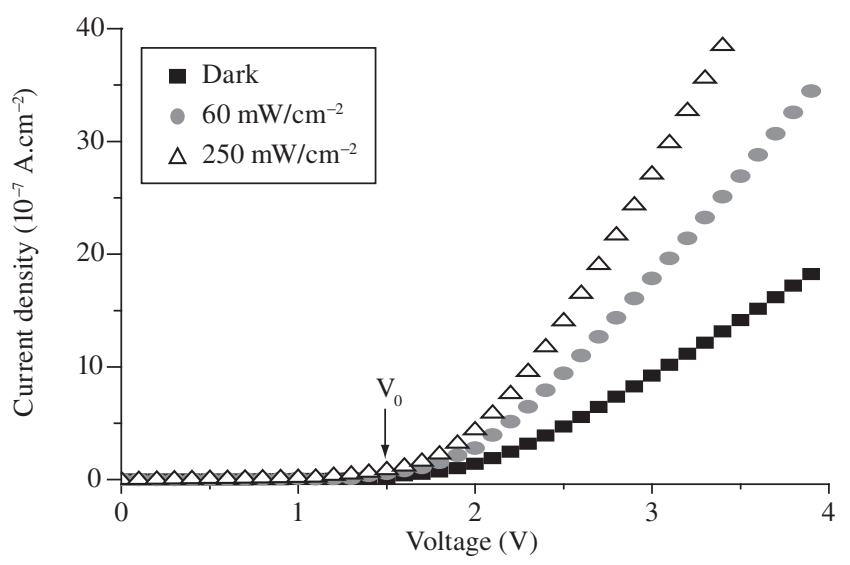

Figure 2. Current density vs. voltage (J vs. V) curves of ITO/MH-PPV/Al structure performed in vacuum and under different illumination conditions (dark, $60 \mathrm{~mW} \cdot \mathrm{cm}^{-2}$ and $250 \mathrm{~mW} \cdot \mathrm{cm}^{-2}$ ).

potential of MH-PPV (5.2 eV) and work functions of the Au or ITO (around $5.1 \mathrm{eV}$ ).

Figure 3 shows the frequency dependence of the real, $Z^{\prime}(f)$, and imaginary, Z"(f), components of the complex impedance of both $\mathrm{Au} / \mathrm{MH}-\mathrm{PPV} / \mathrm{Au}$ and ITO/MH-PPV/Al samples. The measurements were carried out in the dark for Au-Au (Figure 3a), and in the dark (Figure 3b), and at $60 \mathrm{~mW} . \mathrm{cm}^{-2}$ (Figure 3c) and at $250 \mathrm{~mW} \cdot \mathrm{cm}^{-2}$ (Figure 3d) for ITO-Al. At low frequencies we have observed that real component of $\mathrm{Au}-\mathrm{Au}$ (Figure 3a) exhibits a plateau, at about $8 \mathrm{M} \Omega$ that extends up close to $100 \mathrm{~Hz}$. Beyond this frequency, denominated here as the critical frequency $\mathrm{f}_{\mathrm{c}}, \mathrm{Z}^{\prime}$ (f) decreased continuously, and at $1 \mathrm{MHz}$ the recorded value of around $50 \Omega$. On the other hand, the imaginary part has showed a broad peak with the maximum around $\mathrm{f}_{\mathrm{c}}$. This is the typical behavior of disordered materials being $\sigma_{\mathrm{dc}}=\mathrm{L} / \mathrm{AZ}_{0}=1.5 \times 10^{-8} \mathrm{~S} / \mathrm{m}$ the dc conductivity of the polymer. For frequencies higher than $10 \mathrm{~Hz}, \mathrm{Z}^{\prime}(\mathrm{f})$ and Z'(f) of ITO-Al sample presented a similar $\mathrm{Au}$-Au behavior. However, the $\mathrm{f}_{\mathrm{c}}$ increased while the $Z^{\prime}$ (f $f_{c}$ ) decreased with increasing light intensity. Moreover, Z'(f) and Z" (f) increased when $\mathrm{f} \rightarrow 0$, and Z"'(f) presented a minimum at about $10 \mathrm{~Hz}$ in dark condition which shift towards higher frequencies with illumination. These results suggest that the interface Al/MH-PPV dominates the real and imaginary components of the impedance at lower frequencies (below $\mathrm{f}_{\mathrm{c}}$ ), while the polymer film dominates at higher frequencies (above $f_{c}$ ). Full lines in Figure 3 represent the theoretical-experimental fittings obtained from Equation 2, as discussed in section 4 .

\section{A Model for Complex Impedance}

The clear distinction between bulk and interface effects on the complex impedance suggested through the results showed in Figure 3 makes it possible to assume the total impedance $\left(Z^{*}\right)$ of ITO/MH-

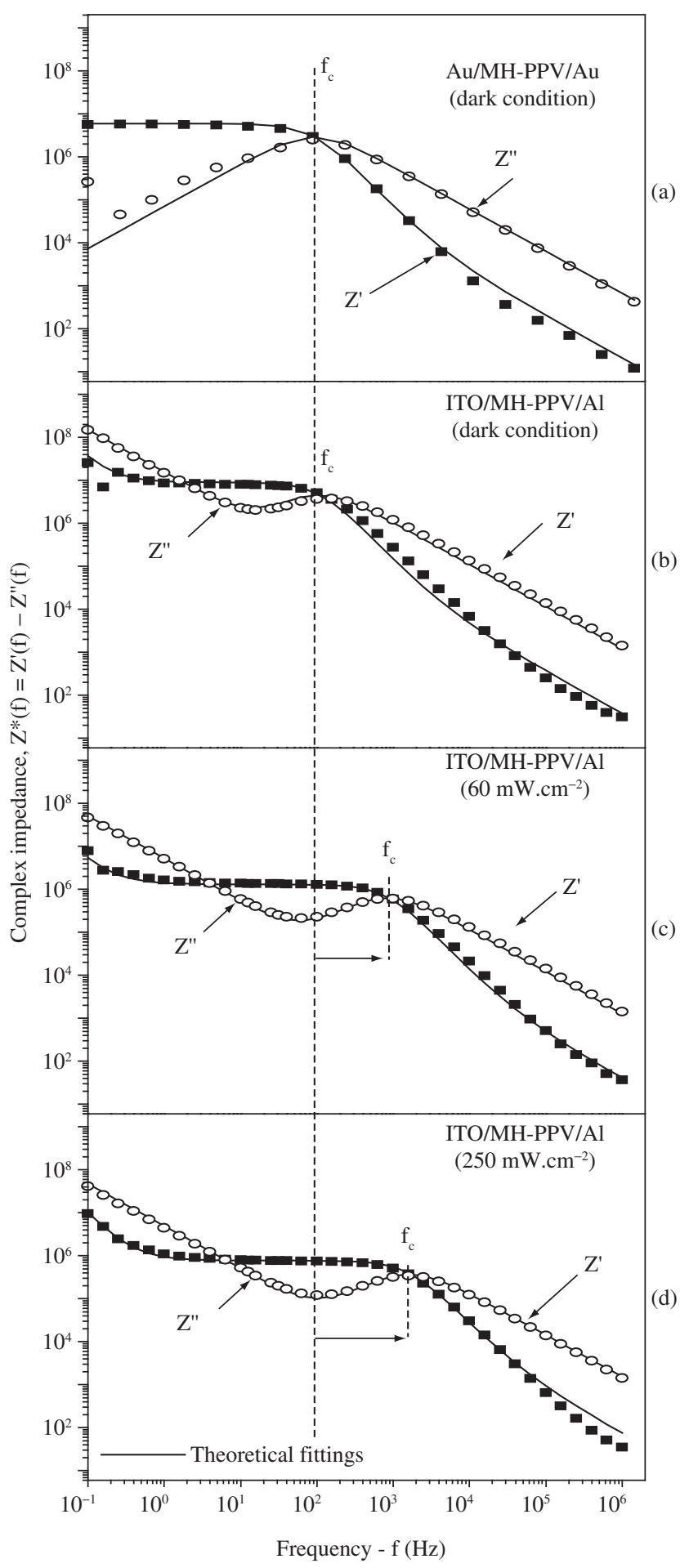

Figure 3. Real, Z'(f), and imaginary, Z"(f), components of the complex impedance for $\mathrm{Au} / \mathrm{MH}-\mathrm{PPV} / \mathrm{Au}$ and ITO/MH-PPV/Al samples. The measurements were carried out in the dark for Au-Au (Figure 3a) sample, and in the dark (Figure 3b), at $60 \mathrm{~mW} \cdot \mathrm{cm}^{-2}$ (Figure 3c) and at $250 \mathrm{~mW} \cdot \mathrm{cm}^{-2}$ (Figure 3d) for ITO-Al one.

PPV/Al diodes as an expression based on the series combination of bulk impedance of MH-PPV film $\left(Z^{*}\right.$ p $)$, the impedance of Al/MH-PPV interface layer $\left(Z^{*}\right)$ and the resistance of ITO $\left(Z^{*}{ }_{\text {ITO }}\right)$, such that:

$$
Z^{*}=Z_{I}^{*}+Z_{P}^{*}+Z_{\text {ITO }}
$$


We further assume $Z^{*}, Z^{*}$ and $Z^{*}{ }_{\text {IтO }}$ to represent a combination of a resistor in parallel with a capacitor obeying the Cole-Cole expression $^{10}$, and Equation 1 becomes:

$$
\mathrm{z}^{*}(f)=\frac{\mathrm{R}_{\mathrm{I}}}{1+\left(\mathrm{i} 2 \pi f \mathrm{R}_{\mathrm{I}} \mathrm{C}_{\mathrm{I}}\right)^{\alpha_{I}}}+\frac{\mathrm{R}_{\mathrm{P}}}{1+\left(\mathrm{i} 2 \pi f \mathrm{R}_{\mathrm{P}} \mathrm{C}_{\mathrm{P}}\right)^{\alpha_{\mathrm{P}}}}+\mathrm{R}_{\mathrm{ITO}}
$$

where $\mathrm{f}$ is the electrical-field frequency and the parameters $\alpha_{\mathrm{I}}$ and $\alpha_{\mathrm{p}}$ simulate distributions of relaxation times of the MH-PPV and Al/ MH-PPV, such that $0 \leq \alpha_{p}, \alpha_{i} \leq 1$. Of course, when $\alpha_{i}=\alpha_{p}=0$, we have the classical Debye process ${ }^{10}$ (or single time constant).

\section{Discussion}

The full-line curves in Figure 3 show the fitting of the experimental results obtained using Equation 2 for samples with $\mathrm{Au}-\mathrm{Au}$ and ITO-Al electrodes in the dark, as well as for ITO/MH-PPV/Al sample also under illumination, with the adjusted parameters values given in Table 1. It is observed that $\mathrm{R}_{\mathrm{p}}$ for ITO-Al sample varied from $6 \mathrm{M} \Omega$ (dark) to $7.7 \times 10^{5} \Omega$ (under higher illumination conditions), and therefore its polymer film parameters obtained in the dark are similar to those obtained for Au-Au sample at the same condition. This result suggests that the impedance of the MH-PPV film on ITO/MH$\mathrm{PPV} / \mathrm{Al}$ device decreases with the light intensity, as expected from the analysis of Figure 2, in which the tangent $\mathrm{dJ} / \mathrm{dV}$ increased with increasing light intensity. In addition, the capacitance and resistance of the interface is higher than the values obtained from the polymer, and almost all parameters decreased with increasing light intensity. These results suggest that the illumination acts increasing $\mathrm{Ci}$ and decreasing $\mathrm{R}_{\mathrm{p}}, \mathrm{C}_{\mathrm{p}}, \mathrm{R}_{\mathrm{i}}$, and thus the electrical resistivity of both polymer and interfacial layer $(\rho \approx A R / L$,$) and dielectric constant \left(k p \approx C_{p} L / \varepsilon_{0} A\right)$ of the polymer, as well as the electrical resistance and the thickness of the Al/MH-PPV interfacial layer $\left(\mathrm{L}_{\mathrm{i}} \approx \varepsilon_{0} \mathrm{~A} / \mathrm{C}_{\mathrm{p}}\right)$. Assuming that the electrical conductivity of material is directly proportional to the charger carrier mobility $(\mu)$ and to the density of charge carriers (n), $(\sigma \propto \mu \mathrm{n})$, that $\sigma / \gamma_{\min }$ is proportional to $(1 / \mathrm{R}) /(1 / \tau)$, where, $\sigma$ is the conductivity, $\tau$ the relaxation time $(\tau=\mathrm{RC}), \mathrm{R}$ the resistance and $\mathrm{C}$ the capacitance, $(\mathrm{C}=\mathrm{Q} / \mathrm{V})$, where $\mathrm{Q}$ it is the amount of charge that can be storage at a capacitor with a capacitance $\mathrm{C}$ and a voltage $\mathrm{V}$. One can say that $\sigma / \gamma_{\min }$ is proportional to $\mathrm{C}$ so the higher the conductivity is the higher the capacitance will be. If $\mathrm{C}_{\mathrm{i}}$ increases it leads to an increase of the amount of charge storage hence the voltage is constant. It leads to an increase of the density of charge carriers, confirmed by the decreases of the electrical resistivity, as well-known for photoconductive material, in which the density of photo-generated charges carriers is directly proportional to light intensity.

\section{Conclusions}

In this work we showed the influence of intensive light exposure on the real and imaginary components of the complex impedance of polymer light-emitting diodes. It was observed that the electrical behavior of this device is controlled not only by the bulk properties of thin MH-PPV films, but also by the Al/MH-PPV interfacial layer. In order to obtain an expression to explain the experimental results, it was used a combination of resistor-capacitor circuits thereby separating bulk from interface contributions. Following the hint suggested by the parameters showed in Table 1, the dark conductivity and dielectrics constant of the polymer film, around $10^{-8} \mathrm{~S} / \mathrm{m}$ and 3 , are in agreement with literature ${ }^{8,9}$, and thus a rough estimation for the thickness of the $\mathrm{Al} / \mathrm{MH}-\mathrm{PPV}$ layer may be obtained as few nanometers. Furthermore, the incident light provides photo-generated charger carriers at the bulk level increasing the conductivity, evidencing the photo-conductivity of material.

\section{Acknowledgments}

This work was sponsored by FAPEMIG, Fapesp and CNPq and IMMP/CNPq.

\section{References}

1. Burroughes JH., Bradley DDC., Brown AR., Marks RN., Mackay K., Friend RH., Burns PL., Holmes AB. Light-emitting diodes based on conjugated polymers. Nature 1990; 347(6293):539-541.

2. Arkhipov VI., Emelianova EV., Tak YH., Bässler H. Charge carrier transport and recombination at the interface between disordered organic dielectrics. Journal of Applied Physics 1998; 84(2):848-856.

3. Davids PS., Campbell IH., Smith DL. Device model for single carrier organic diodes. Journal of Applied Physics 1997; 82(12):6319-6315.

4. Brütting W., Berleb S., Mückl AG. Device physics of organic lightemitting diodes based on molecular materials. Organic Electronics 2001; 2(1):1-36.

5. Bianchi RF., Cunha HN., Faria RM., Leal Ferreira GF., Mariz G., Neto J. Electrical studies on the doping dependence and electrode effect of metal-PANI-metal structures. Journal of Physics D: Applied Physics 2005; 38(9): 1437-1443.

6. Santos LF., Bianchi RF., Faria RM., Mergulhão S. Photogenerated carrier profile determination in polymeric light-emitting diodes by steady-state and transient photocurrent measurements. Materials Science Engineering: B 2006; 135(2):103-107.

7. Bianchi RF., Balogh DT., Tinani M., Faria R., Irene EA. Ellipsometry study of the photo-oxidation of poly[(2-methoxy-5-hexyloxy)-pphenylenevinylene]. Journal of Polymer Science Part B: Polymer Physics 2004; 42(6): 1033-1041.

8. Santos LF., Bianchi RF., Faria RM. Electrical properties of polymeric light-emitting diodes. Journal of Non- Crystalline Solids 2004; 338-340:590-594.

9. Bianchi RF., Santos LF., Faria RM. Complex Resistivity of polymer light emitting diodes. In $11^{\text {th }}$ International Symposium on Electrets- ISE 11; 2002. Melbourne: International Symposium on Electrets Proceedings; 2002, v.11. p. 359-362.

10. Böttcher CJF., Bordewijk P. Theory of electric polarization. 1st ed. Local: Elsevier Scientific Publishing Company; 1978. v.II. p.62.

Table 1. Data of fittings between Equation 2 and experimental results for Au/MH-PPV and ITO/MH-PPV/Al exposed to different light intensities. For all fitting it was obtained $\alpha_{\mathrm{P}}=\alpha_{\mathrm{I}}=0.98$ and $\mathrm{R}_{\mathrm{ITO}} \sim 30 \Omega$.

\begin{tabular}{lccccccccc}
\hline \multicolumn{1}{c}{ Sample } & $\begin{array}{c}\text { Light intensity } \\
\left(\mathrm{mW} . \mathrm{cm}^{-2}\right)\end{array}$ & $\mathrm{R}_{\mathrm{p}}(\Omega)$ & $\mathrm{R}_{\mathrm{i}}(\Omega)$ & $\mathrm{C}_{\mathrm{p}}(\mathrm{F})$ & $\mathrm{C}_{\mathrm{i}}(\mathrm{F})$ & $\rho_{\mathrm{p}}(\Omega \mathrm{cm})$ & $\mathrm{L}_{\mathrm{i}}(\mathrm{m})$ & $\tau_{\mathrm{p}}\left(\mathrm{Hz}^{-1}\right)$ & $\tau_{\mathrm{i}}\left(\mathrm{Hz}^{-1}\right)$ \\
\hline Au/MH-PPV/Au & Dark & $6.0 \times 10^{6}$ & - & $1.8 \times 10^{-9}$ & - & $4.5 \times 10^{10}$ & - & $1.1 \times 10^{-2}$ & - \\
ITO/MH-PPV/Al & Dark & $9.0 \times 10^{6}$ & $9.0 \times 10^{8}$ & $1.0 \times 10^{-9}$ & $6.6 \times 10^{-8}$ & $6.7 \times 10^{10}$ & $4 \times 10^{-9}$ & $9.0 \times 10^{-3}$ & 59.4 \\
ITO/MH-PPV/Al & 60 & $1.3 \times 10^{6}$ & $8.0 \times 10^{8}$ & $9.0 \times 10^{-10}$ & $2.0 \times 10^{-7}$ & $9.8 \times 10^{9}$ & $1.3 \times 10^{-9}$ & $1.2 \times 10^{-3}$ & 160 \\
ITO/MH-PPV/Al & 250 & $7.7 \times 10^{5}$ & $2.6 \times 10^{8}$ & $7.9 \times 10^{-10}$ & $2.1 \times 10^{-7}$ & $5.6 \times 10^{9}$ & $1.2 \times 10^{-9}$ & $6.1 \times 10^{-4}$ & 54.6 \\
\hline
\end{tabular}

